\title{
Alicyclic polyamide nanofilms with asymmetric structure for Cl-/SO42- separation
}

\author{
Bingbing Yuan ${ }^{1}$, Shanshan Zhang ${ }^{1}$, Chi Jiang ${ }^{1}$, Ping $\mathrm{Hu}^{1}$, Jiabao Cui ${ }^{1}$, Siheng Zhao ${ }^{1}$, Ning \\ Wang $^{1}$, and Q. Jason Niu ${ }^{2}$ \\ ${ }^{1}$ Affiliation not available \\ ${ }^{2}$ Shenzhen University
}

March 26, 2021

\begin{abstract}
Separation of mixed ion, especially Cl- and SO42-, is essential for reduced energy consumption and achievement of the minimal or zero-liquid discharge. Membrane technology has attracted significant attention in this respect owing to its good system coupling and maturity. However, it remains challenging to fabricate highly selective nanofilm with fine-tuning pore and structure that is suitable for the separation of Cl- and SO42-. Herein, we report an asymmetric alicyclic polyamide nanofilm with enhanced interconnectivity pore by manipulating the molecular geometry structure, composed of the porous aromatic polyamide dendrimer layer, and the dense alicyclic polyamide layer with hollow stripes. This resulted membrane shows a $107.14 \%$ separation rate of Cl- and SO42-, and a water flux (for Na2SO4) of 2.2 times that of the pristine polyamide membrane. We estimate this fine-tuning pore approach resulting from alicyclic structure also might be employed in other separation membranes such as gas, solvent or neutral molecules.
\end{abstract}

\section{Hosted file}

Manuscript.pdf available at https://authorea.com/users/404253/articles/515510-alicyclicpolyamide-nanofilms-with-asymmetric-structure-for-cl-so42-separation

\section{Hosted file}

Manuscript.pdf available at https://authorea.com/users/404253/articles/515510-alicyclicpolyamide-nanofilms-with-asymmetric-structure-for-cl-so42-separation 